\title{
Effects of the 'Nella Dan' oil spill on the fauna of Durvillaea antarctica holdfasts
}

\author{
S. D. A. Smith, R. D. Simpson \\ Zoology Department, University of New England, Armidale, N.S.W. 2351, Australia
}

\begin{abstract}
The effects of a small spill of light marine diesel on the community structure of invertebrates inhabiting Durvillaea antarctica holdfasts were examined for samples taken from sites which received heavy, moderate and no oiling at Macquarie Island, sub-Antarctic. Non-metric multidimensional scaling (MDS) at both the species and a mixed taxonomic level separated samples collected at oiled sites from the controls. Pre-impact data were only available for 1 of the heavily oiled sites and these samples grouped with those from control sites in MDS analysis. Holdfasts from oiled sites were characterised by heavy sediment loads, a dominance of capitellid, cirratulid and spionid polychaetes and the rarity of the isopod Limnoria stephenseni. In contrast, samples from the control sites were dominated by peracarid crustaceans and in partıcular by the herbivorous isopod $L$. stephenseni. Analysis of differences in the size distribution patterns of the 4 most common species (the isopod L. stephenseni, the amphipods Parawaldeckia kidderi and Hyale novaezealandiae and the gastropod Laevilittorina caliginosa) suggests that impacts occurred across all sizes for $L$. stephenseni and P. kidderi. At the heavily oiled sites, size distribution patterns for the gastropod L. caliginosa were skewed towards larger individuals, suggesting a differential mortality of smaller individuals. We suggest that the rarity of $L$. stephensenj at the oiled sites may result in the accumulation of sediment within the internal chambers of the holdfast, producing a habitat more suitable for polychaete worms. The residual levels of hydrocarbons within these sediments may further restrict the polychaete species to opportunistic taxa which were not found at the control sites. As this study did not include pre-impact sampling, the interpretation of the results is partially confounded with possible, unmeasured, preexisting site-specific differences in the community structure. While the availability of pre-impact data from 1 oiled site (from an earlier study) has strengthened interpretation with respect to possible oil effects, further sampling of the sites is needed to resolve some of these uncertainties
\end{abstract}

KEY WORDS: Oil spill $\cdot$ Sub-Antarctic $\cdot$ Holdfast macrofauna Community effects

\section{INTRODUCTION}

The grounding of the Australian Antarctic re-supply vessel 'Nella Dan' at Macquarie Island in December 1987 has provided one of the few opportunities to evaluate human impact on marine communities at high latitudes in the southern hemisphere. While the marine benthic communities of the Antarctic and southern ocean regions are well documented (for Macquarie Island: Kenny \& Haysom 1962, Bennett 1971, Simpson 1976a, b, 1977, 1988, Lowry et al. 1978, Lowry \& Fenwick 1983, Lowry \& Stoddart 1983), few data are available on the way in which these communities may respond to disturbances from human activities. The results of ecological studies at different latitudes suggest that recovery of communities may be slower in polar regions due to reproductive factors such as limited breeding season, low fecundities and the lack of wide-ranging larval stages for many species (Michael 1977). Thus high latitude communities may be particularly sensitive to pollution events such as oil spills.

The grounding of the 'Nella Dan' resulted in the release of 2700001 of oil, mostly light marine diesel, into the sea on the northeastern coast of Macquarie Island $\left(54^{\circ} 29^{\prime} \mathrm{S}, 158^{\circ} 58^{\prime} \mathrm{E}\right)$. Oil was blown onshore for the first $26 \mathrm{~h}$ following the grounding, with a change in weather pattern blowing the oil out to sea thereafter (Hamilton 1988, Pople et al. 1990). Large mortalities of marine invertebrates were evident within the first few days following the oil spill, with 
thousands of animals washed ashore along a $2 \mathrm{~km}$ stretch of coastline immediately north of the grounding site.

As part of an investigation into the biological impact of the oil spill, intertidal surveys were conducted 1 yr after the oil spill (over the summer of 1988-89) to determine if there were differences in biotic patterns between areas that received oil and control locations (Pople et al. 1990). Those studies were made more interpretable as historic data were available for some sites from earlier work on intertidal zonation by Kenny \& Haysom (1962) and Simpson (1976a). The results of the intertidal study indicated that there were marked reductions in the abundance of marine invertebrates in the lower littoral zones at oiled locations when compared to the controls (Pople et al. 1990). More specifically, effects were localised to the kelp and lower red zones (these zones sensu Kenny \& Haysom 1962, Simpson 1976a). The upper intertidal areas showed little difference among sites, which suggested minimal impact in these areas.

Durvillaea antarctica holdfasts were collected during the 1989 field programme, as previously published studies from the UK (Jones 1971, 1972, Moore 1972 , 1973a, b, 1974, Sheppard et al. 1980) and work in progress in New South Wales (Smith \& Simpson 1992, 1993, Smith 1993) had indicated that holdfast macrofaunal communities may be useful in monitoring anthropogenic disturbance.

While the Durvillaea antarctica holdfast samples were collected a year after the oil spill, it was hypothesised that any impact that led to the removal of fauna from the holdfast should be detectable in the age class structures within populations of the common species even if the community composition (as total number of taxa and distribution of abundance among species) had recovered through immigration of fauna from unaffected sites. There are a number of features of the oil spill which add to the likelihood of detecting a substantial impact on the kelp holdfast community. Firstly, the site of the grounding was immediately adjacent to the sampling sites, with strong onshore winds transporting the slick rapidly onto the rocky shore (Hamilton 1988). Thus there was little or no weathering of the diesel prior to contact with the intertidal biota. Secondly, the oil was a light diesel fuel (light marine diesel) which has been shown to have greater biological impact than heavier oils in studies of oil toxicity elsewhere (Moore \& Dwyer 1974, Michael 1977. Rice et al. 1977). Thirdly, the low water temperatures at Macquarie Island are likely to lead to greater persistence of toxic components of the oil through low rates of evaporative loss of the lighter oil fractions. In addition, biodegradation by bacterial activity may be lower in colder waters (Michael 1977.
Rice et al. 1977, Wells \& Percy 1985), although specific studies within the sub-Antarctic have demonstrated an appreciable rate of $59 \%$ (annual mean) for this process during in situ measurements using crude oil (Delille \& Vaillant 1988). Finally, many of the shore organisms inhabiting Macquarie Island have discrete breeding periods and many of the molluscs brood or deposit egg cases rather than producing wide-ranging pelagic larval stages (Simpson 1977, 1982a, b, Simpson \& Harrington 1985). For the holdfast fauna sampled from the control sites, 5 of the 6 most common taxa (which together account for $86 \%$ of the total fauna at these sites) are brooders comprising 4 peracarid crustaceans and a sabellid polychaete (Chone sp., which retains large eggs from which juveniles develop within its sandy tubes; authors' pers. obs.). The other is a gastropod mollusc, which hatches as juveniles from egg masses deposited on the substratum (Simpson \& Harrington 1985). For these species, the recovery of populations at impacted sites is likely to be dependent on migration from unaffected areas rather than the potentially more rapid process of recruitment of pelagic larvae as demonstrated in warmer waters (Michael 1977, Notini 1978)

In addition to providing information on the effects of the 'Nella Dan' oil spill on the invertebrate fauna inhabiting one of the intertidal zones at Macquarie Island, the study also provided the opportunity to present a quantitative description of the Durvillaea antarctica holdfast community. While the Macrocystis pyrifera holdfast habitat and faunal complement has been quantitatively described at some sublittoral sites at Macquarie Island in the past (Edgar 1987), published accounts of the $D$. antarctica holdfast faunal complement have provided no quantitative data (Kenny \& Haysom 1962).

\section{METHODS}

Collection and processing. Thirty-one holdfasts were collected from the lower intertidal area of 5 sites within 3 locations: the heavily oiled area - Buckles Bay and Garden Cove (the Oil 1 location of Pople et al. 1990); the moderately oiled area - Secluded Bay (Oil 2 location of Pople et al. 1990); and a control area - Sandy Bay (Control 2 of Pople et al. 1990) (Fig. 1).

Holdfasts were collected at low tide when sea conditions were calm. After removal of the fronds, the holdfast was levered from the rock with a crowbar or knife and placed in a plastic bag together with any material remaining on the underlying rocky substratum. Care was taken to minimise loss of sediment and other material during the sampling procedure. Holdfasts and contents were stored in $10 \%$ buffered formalin 
a

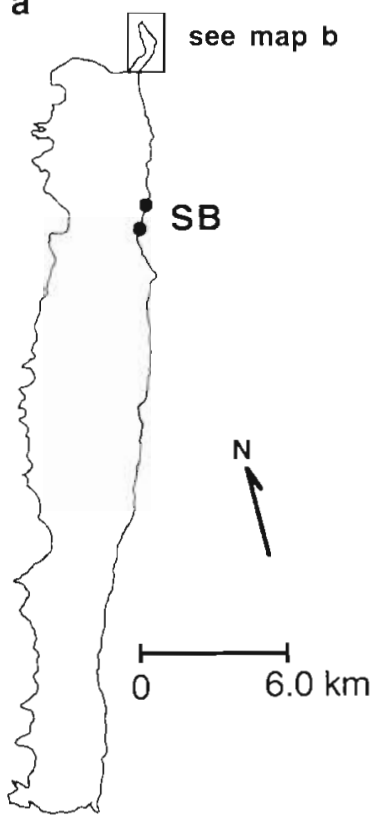

b

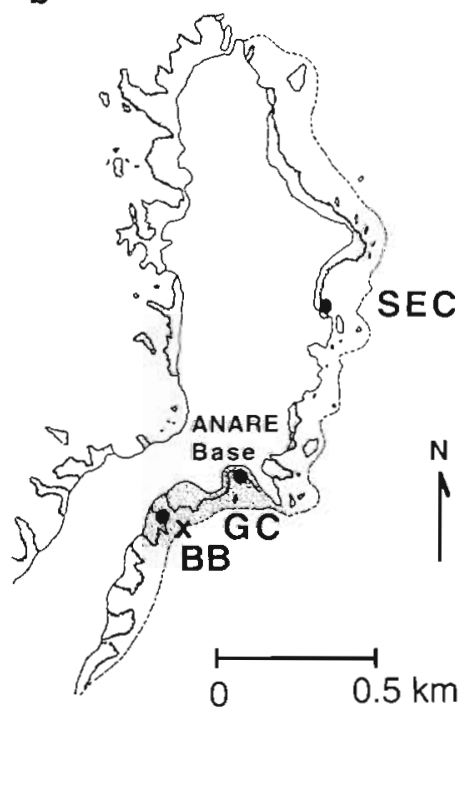

Fig. 1. Macquarie Island in the sub-Antarctic showing holdfast sampling sites. (a) Sites within the control location at Sandy Bay (SB), (b) sites in the isthmus area: BB (Buckles Bay) and GC (Garden Cove) in the most heavily oiled area and SEC (Secluded Bay) in the moderately oiled area. The site of the 'Nella Dan' grounding (X), extent of the oil spill (dashed line) and most heavily oiled areas (stippling) are also shown

Unlike many members of the Laminariales (e.g. Macrocystis, Ecklonia in Australian waters), the holdfast of Durvillaea antarctica (Durvillaeales) is not composed of intertwining hapteron branches but is discoid and solid. The dissection method for $D$. antarctica samples was not as simple as for studies using other holdfasts (where sequential removal of haptera provides a method of carefully extracting the fauna, e.g. Ecklonia radiata; Smith \& Simpson 1992, Smith 1993) and involved cutting the holdfast into sections of approximately $10 \mathrm{~mm}$ width. Each section was carefully examined and further dissected if necessary to remove all the macrofauna $(\geq 1 \mathrm{~mm})$. Specimens were sorted to the lowest taxonomic level possible (species for most taxa), counted and weighed (fresh weight). A representative collection of fauna has been deposited with the Australian Museum in Sydney.

A. number of physico-chemical measurements were made for each holdfast sample. Sediment content was measured by determining the dry weight of the material passing through a $1 \mathrm{~mm}$ sieve. Sediment samples were analysed for total polyaromatic hydrocarbon (PAH) content using UV absorption spectrophotometry (Henig 1979). The volume of the holdfast was also measured using water displacement (Smith \& Simpson 1992).

The overall statistical model for the sampling programme was an unbalanced nested design with 2 sites within the area of heaviest oiling: Buckles Bay, $\mathrm{n}=6$, and Garden Cove, $\mathrm{n}=5 ; 2$ sites within the control treatment: Sandy Bay site 1 and Sandy Bay site 2, n = 5 for both; and 10 replicate samples taken from 1 site where moderate oiling occurred. Secluded Bay (Fig. 1).

Analysis of community structure. The analytical procedure followed the protocol recommended by a number of authors in the recent marine ecological literature (Field et al. 1982, Gray et al. 1988, Clarke 1993, Warwick 1993). The protocal consists of the following steps: (1) displaying community patterns through non-parametric multivariate methods (ordination and/or clustering), (2) determining if the benthic community at any site is displaying signs of stress, (3) identifying the species which are primarily responsible for the sample groupings, (4) testing the differences statistically, and (5) correlating the patterns of spatial variation in the biological variables with measures of the pollution/perturbation gradient.

Because of differences in the size of each individual sample (holdfast volume), raw abundance data were standardised prior to analysis (Smith \& Simpson 1993). Data were subsequently root-root transformed and similarities between each pair of samples calculated using the Bray-Curtis measure (Bray \& Curtis 1957). The spatial relationship between samples was determined using non-metric multidimensional scaling (MDS) analysis with the results displayed in a 2-dimensional plot. As a number of recent studies have suggested that the effects of pollution are detectable at higher taxonomic levels (Warwick 1988a, b, Smith \& Simpson 1993), MDS analyses were also conducted for data aggregated to a mixed taxonomic level where each category represents a distinct faunal group (i.e. at the level of class with the Malacostraca subdivided into component orders; Smith \& Simpson 1993, Smith 1994).

The community data were analysed for signs of stress using 3 separate methods: abundance biomass comparisons (ABC) (Warwick 1986), log-normal plots (Gray \& Pearson 1982) and the Ewens-Caswell neutral model (Platt \& Lambshead 1985, Lambshead \& Platt 1988). Three methods were used as recent studies have suggested that interpretations based on more than 1 method may be more reliable, as each has been demonstrated to provide equivocal results under certain conditions (Dauer et al. 1993, Warwick 1993 Smith 1994, Warwick \& Clarke 1994). Data were pooled across samples within a site for both the $A B C$ 
and log-normal methods. While this does not pose problems for the $A B C$ method, the differences in the number of samples between sites could confound the interpretation of the log-normal plots. As the minimum number of samples available for any site was 4 (see 'Results'), log-normal curves were constructed from 4 randomly selected samples for sites where $n>4$.

Differences in species composition between sites were evaluated using both non-parametric (SIMPER, similarity percentages; Clarke 1993) and parametric methods (ANOVA). All species were included in the SIMPER analyses but only the common species were evaluated in the ANOVA (common species were defined as those with a proportional representation of $4 \%$ or greater in any one sample; Field et al. 1982 , Smith 1994, Table 1).

Tests for the significance of differences between the different treatments were performed using the randomisation/permutation procedure ANOSIM (analysis of similarities; Clarke 1993). The relationship of the observed faunistic patterns to the 3 physico-chemical variables (sediment, PAH, holdfast volume) was explored by superimposing the data for these variables on the sample data points and also by using the procedure BIO-ENV (Clarke \& Ainsworth 1993). BIO-ENV is a method which provides a measure of correlation between separate ordinations of biotic and abiotic data and can be used to determine which abiotic variables best explain the structure within the biological data (Clarke 1993, Clarke \& Ainsworth 1993). In addition, correlations between the dominance of the common species and the 3 abiotic variables were conducted in order to determine specific relationships for the domi-

Table 1. List of species with a proportional representation of $4 \%$ or greater in any one Durvillaea antarctica holdfast sample

\begin{tabular}{|ll|}
\hline Species & Taxonomic group \\
\hline Nematodes & Nematode \\
Platyhelminth sp. 1 & Platyhelminth \\
Nemerteans & Nemertean \\
Oligochaete sp. 1 & Oligochaete \\
Capitella capitata' & Polychaete \\
Sf. Syllinae sp. 1 & Polychaete \\
Sf. Eusyllinae sp. 1 & Polychaete \\
Spirorbis aggregata & Polychaete \\
Chone sp. & Polychaete \\
Boccardia sp. & Polychaete \\
Dodecaceria sp. & Polychaete \\
Laevilittorina caliginosa & Gastropod \\
Kerguelenella lateralis & Gastropod \\
Vermectias nelladanae & Isopod \\
Limnoria stephenseni & Isopod \\
Parawaldeckia kidderi & Amphipod \\
Hyale novaezealandiae & Amphipod \\
Mite sp. & Mite \\
\hline
\end{tabular}

nant taxa. For these analyses, species abundance data were standardised and arcsine transformed and the abiotic variables were $\log _{10}$ transformed.

Population level analyses. As one of the objectives of the study was to evaluate the effects of the oil spill at the population level through comparisons of size class data, the sizes of all individuals of the 4 most common, ubiquitous species were determined. These species were the gastropod mollusc Laevilittorina caliginosa, the amphipods Hyale novaezealandiae and Parawaldeckia kidderi and the isopod Limnoria stephenseni. While body size determinations were straightforward for $L$. caliginosa (the maximum distance from the tip of the spire to the anterior lip of the aperture), fixed specimens of peracarid crustaceans can show a range of flexion, from individuals that are straight, through to those that are completely curled, making the measurement of total length difficult. For $P$. kidderi, flexion was relatively uniform and so total body length measurements were determined for this species (from the rostrum to the base of the telson). Flexion was much less uniform for the other 2 species and so the length of the head (from the tip of the rostrum to the posterior margin of the head segment) was measured for each individual. Total body length was later extrapolated from a regression analysis of the relationship between head length and total body length, the latter determined from camera lucida projection for 20 specimens of each species (Fenwick 1985).

Age class structure was examined by plotting measured size against cumulative frequency scaled to a percentage and determining where inflexions occurred within the resultant curves (Cassie 1954). However, in all cases this method proved to rely on rather subjective evaluation as to the position of inflexions and the simpler method of examining histograms of size data was found to be more informative. Intervals for size classes were set by attempting to allocate obvious peaks in the size frequency distribution into separate classes (note that these do not necessarily correspond to distinct age classes). Size frequency distributions were compared graphically between treatments and the difference in the mean size of individuals was tested using 2-way nested ANOVA and planned comparisons. Pooling of mean squares was performed (site within location with residual) where appropriate (Sokal \& Rohlf 1981) if the first tests for a location effect (location tested over site within location) were not significant. Contingency table testing of the distribution of individuals among size classes was not performed die to problems of non-independence and the requirement to perform 'sacrificial pseudoreplication' (Hurlbert 1984) in order to provide a comparison across treatments. 


\section{RESULTS}

Although 31 samples were collected for this study, the long storage period (from February 1989 to July 1993) coupled with the large size of the holdfast samples resulted in poor preservation of some material. Where poor preservation was suspected, samples were omitted from analyses in order to minimise the effect of this potentially confounding factor. A total of 7 samples were consequently discarded, with the remaining samples distributed as follows: heavily oiled location Buckles Bay, $\mathrm{n}=4$, Garden Cove, $\mathrm{n}=4$; moderately oiled location - Secluded Bay, $\mathrm{n}=7$; control - Sandy Bay site 1, $n=5$, Sandy Bay site 2, $n=4$.

\section{Description of the holdfast habitat}

The holdfast of Durvillaea antarctica is formed from the outer layer (meristoderm) of the plant through tangential division. The shape is scutate to discoid and is enlarged through the annual addition of new tissue (Chapman \& Chapman 1973). Holdfasts from adjacent plants are often fused, resulting in large, single discs with diameters of up to $60 \mathrm{~cm}$ bearing multiple fronds (Chapman \& Chapman 1973, Ricker 1987). A description of the holdfast habitat for samples collected from the control sites follows.

All samples displayed bioerosion within the central sections of the holdfast which appeared to be associated with the activities of the herbivorous isopod Limnoria stephenseni. The central area of the holdfast usually comprised a large chamber from which numerous tunnels radiated into the surrounding tissues. In most holdfasts, a number of tunnels penetrated to the exterior resulting in small openings in the otherwise smooth and solid dorsal surfaces. Smaller chambers were also located at intervals in some of the tunnels and these were most often associated with aggregations of very small juvenile $L$. stephenseni (body size of approximately 2 to $4 \mathrm{~mm}$ ) each of which was found in individual tunnels leading off from the chamber. Other species were uncommon within the tunnels although specimens of Parawaldeckia kidderi and Laevilittorina caliginosa were occasionally present in or adjacent to the distal end of the tunnel. However, this may represent an artefact resulting from specimens moving deeper into the holdfast to avoid formalin fixation.

Internally, there were a number of subhabitats which were consistent throughout all samples. In the base, adjacent to the rocky substratum, the holdfast was honeycombed and brittle with no living tissue. Most of the sediment present within the holdfast was contained within this layer. This subhabitat was where the majority of the worms (platyhelminthes, polychaetes, oligochaetes, nemerteans and nematodes) were found. The larger internal chambers were present immediately above this dead layer although there was considerable variability in the size and number of obvious chambers, some holdfasts supporting 1 large gallery with a network of small tunnels and others with numerous, smaller, linked chambers. The chambers were the main area where the amphipods and the gastropod Laevilittorina caliginosa were found. Most fresh tunnels (tunnels were termed fresh if the internal walls were pale rather than having the darker colour characteristic of regrowth/oxidation as observed in the base of the holdfast; Herriott 1923) contained 1 or more adult specimens of $L$. stephenseni, and on occasions, aggregations of up to 20 small juveniles in situ.

During the dissection of the holdfasts the most obvious difference between sites was the comparatively high sediment content within samples from the oiled locations. In most of these samples the inner chambers, which were free of sediment at the control sites, were full, or partially full, of dark sediment and detached algal material. In addition, whereas samples from control sites were riddled with fresh tunnels and chambers, very few were present in samples from the oiled locations (Fig. 2).

\section{Patterns of community structure}

The results of the MDS analyses at the species and mixed taxonomic levels are shown in Fig. $3 \mathrm{~A} \& \mathrm{~B}$ respectively. The analysis at the species level shows distinct separation of the oiled sites from the controls with the exception of 1 data point from Sandy Bay site 1 which groups with the samples from Buckles Bay. Samples from Secluded Bay show the least intra-site variability, forming a tight grouping towards the bottom of the plot. There is some overlap in the data points for samples from Buckles Bay and Garden Cove which group to the upper left. Stress values are moderately high (Kruskal's stress $=0.139$ ) but fall within the range considered to provide interpretable results without resorting to a higher dimensional solution (Clarke 1993).

The mixed level analysis (Fig. 3B) shows a similar pattern of sample distributions and site groupings except that there is no overlap between the control and oiled sites. Stress values for the mixed level analysis are also within the acceptable range (Kruskal's stress = 0.140 ) as defined by Clarke (1993).

The determination of the statistical significance of differences between sites within locations and among locations was conducted using a 2-way nested ANOSIM. While a sufficient number of permutations was possible to generate a powerful test for the site 

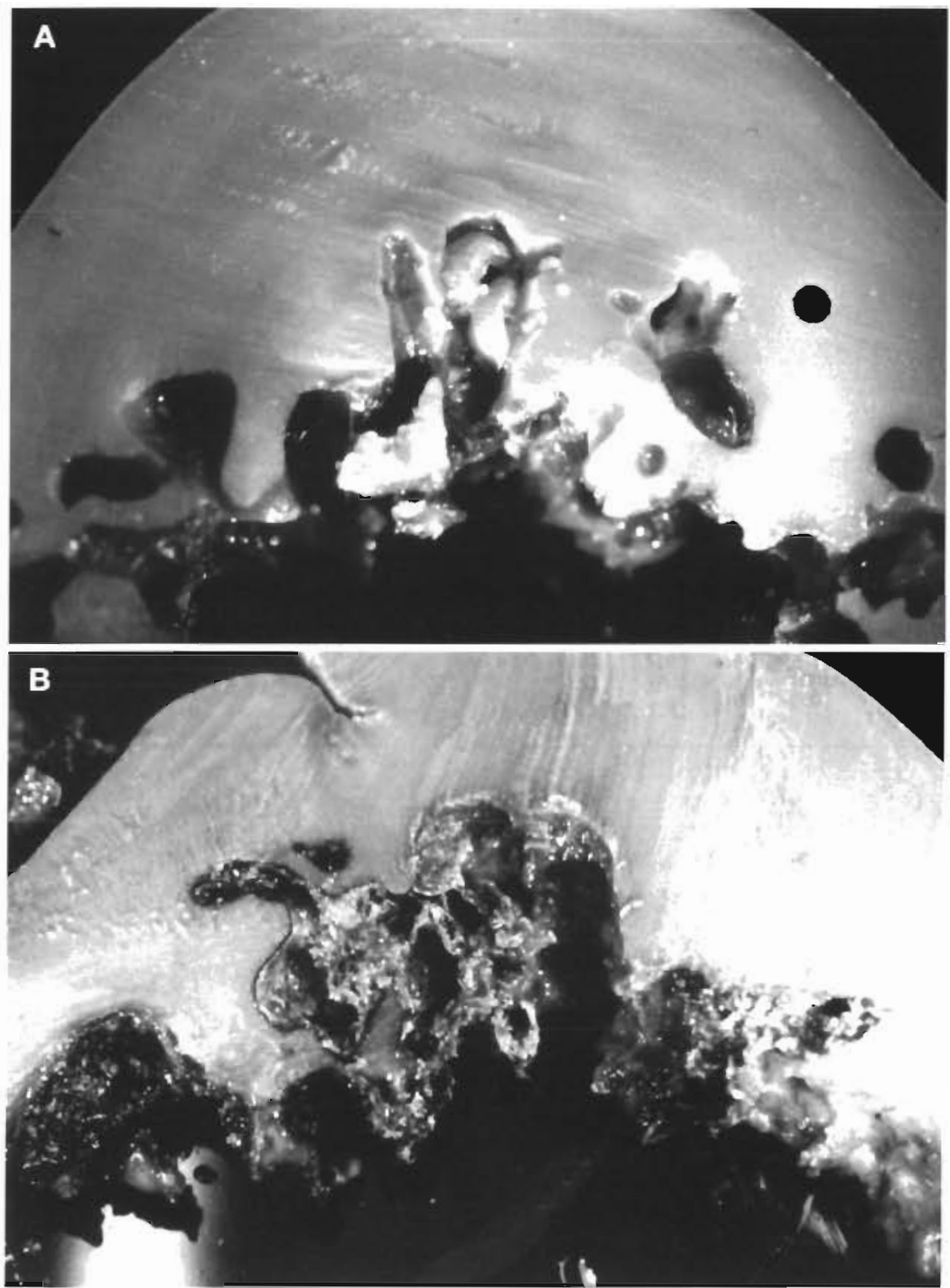

Fig. 2. Cross-sections through Durvillaea antarctica holdfast samples collected from control and oiled sites at Macquarie Island. (A) Internal section of a sample from Sandy Ba.y site 1 showing tunnels and chumbers uxcavated by Limnoria stephenseni with 2 large specimens in situ. (B) Internal srction of a sample from Secluded Bay showing the buld-up of sediment and detached algal material in central tunnels and chambers

within location term (a random sample of 1.000 permutations was used), only 1.5 permutations were available for the location term, resulting in a minimum probability of $6.67 \%$ (i.e. $p=0.067$ ). Thus the test for a location effect had relatively low power. The site within location effect was significant for the analysis at the species level ( $R=0.465, p=0.024$ ) but not significant at the mixed level ( $R=0.462, p=0.062)$, although the probability in the latter analysis only just failed to reach significance at the $5 \%$ level. Both the species and mixed level analyses of the location effect returned the lowest probability possible $(p=0.067)$. The test statistics (R) for these analyses, however, did show considerable differences (species- $\mathrm{R}=$ 0.669 ; mixed-R $=0.912$ ) with a much higher value in the mixed analysis. The $R$ statistic has a maximum value of 1.0 when all samples within treatments are more similar to each other than to any sample from other treatments (Clarke 1993). The results therefore suggest that the location effect (i.e. oil treatment) is more pronounced in analyses at the mixed level than in those conducted at the species level.

\section{Measurements of stress}

Each of the 3 methods conducted to determine whether or not there was evidence of stress in the holdfast community showed differences between the control and oiled samples. ABC plots are presented in Fig. 4 for data pooled over replicates within each site. Three main configurations are recognised in the interpretation of $A B C$ plots: (1) unperturbed, where biomass lies above abundance for the full length of the curves; (2) moderately perturbed, where curves cross or are coincidental for some of their length; and (3) perturbed, where abundance lies above biomass over the full length of the curves (Warwick 1993). For the control sites, Sandy Bay site 1 shows the unperturbed configuration and Sandy Bay site 2 shows some overlap over the 2 highest ranked taxa with the biomass curve above the abundance curve for the full range of lower ranked species. The samples from Secluded Bay show the moderately perturbed configuration, with the curves initially coincidental and abundance lying above the biomass curve subsequently. The 2 sites from the most heavily oiled location (Garden Cove and Buckles Bay) show considerable intra-location differences, producing the moderately perturbed and unperturbed configurations respectively. Examination of the $\mathrm{ABC}$ plots for each individual sample from each site indicated that: (1) with the exception of 2 samples which showed some crossing over species ranks 1 and 2, all samples from Sandy Bay had the unperturbed configuration, (2) all samples from both Garden Cove and Secluded Bay showed either the crossed or perturbed configuration, and (3) one of the samples from Buckles Bay showed 

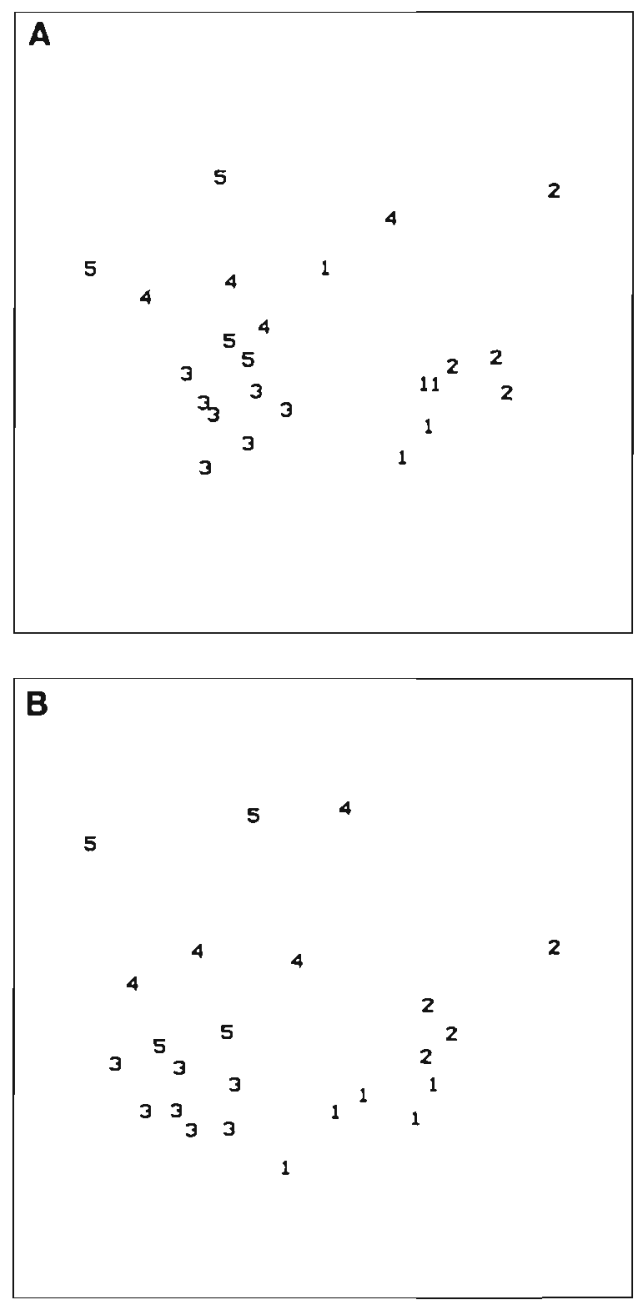

Fig. 3. MDS plots for analyses conducted at the species level and at a mixed taxonomic level (at the level of class with the Malacostraca subdivided into component orders) for all samples from each site. (A) Species level, Kruskal's stress =0.139; (B) mixed taxonomic level, Kruskal's stress $=0.140$. Symbols: $1=$ Sandy Bay site 1, 2 = Sandy Bay site 2, 3 = Secluded Bay, $4=$ Buckles Bay, $5=$ Garden Cove. As the analysis was non-metric, axis scales are arbitrary and are therefore omitted

the perturbed configuration, with the other three revealing the unperturbed pattern.

The log-normal plots (Fig. 5) indicate that the samples from the control sites have a greater percentage of rare species and span fewer geometric classes (to class 10) than samples from the oiled sites (to classes 11 and 12). This conforms to expectations for comparisons between stressed and unstressed communities (Gray \& Pearson 1982).

The results of the Ewens-Caswell neutral model analysis are summarised graphically in Fig. 6. Samples from the oiled locations have greater negative deviations from the diversity values expected under the null hypothesis of no species interactions. In addition there is an apparent gradient of the means, with the samples from Secluded Bay showing intermediate values between the control sites and those receiving the heaviest oiling. Because some taxonomic pooling was conducted in the analysis, the data were not examined for the significance of their departures from neutrality and statistical comparisons were limited to evaluating the differences in the value of $V$ between sites within locations and between locations (Smith \& Simpson 1992). Analysis of transformed $V$ statistic data $[\log (V+7)$; Cochran's test $p>0.05$ ] indicated that neither the site within location nor the location term in the analysis was significant (site within location: $F=0.50$, df $=2,19$, p > 0.05; location: $F=5.43, \mathrm{df}=2,2, \mathrm{p}>0.05$ ).

\section{Differences in species composition between sites}

The species primarily responsible for the differences between the treatments were determined using both SIMPER breakdowns and also 2-way nested ANOVA for each of the common species.

The results of the SIMPER analysis are presented in Table 2. The comparisons of both moderately and heavily oiled locations with the controls show similar results. The main differences are the high dominance of polychaetes and low dominance of crustaceans at the oiled sites. Thus Limnoria stephenseni and Vermectias nelladanae were virtually absent from the oiled sites, which were characterised by high abundances of spionid, cirratulid, sabellid and capitellid polychaetes and oligochaetes.

The ANOVA shows similar results, with significant differences among locations for most of the species which were highly ranked in the SIMPER breakdowns. The significant treatment effect was further explored using planned orthogonal comparisons: oiled locations versus control and heavily oiled versus moderately oiled (mean squares pooled where appropriate; Sokal \& Rohlf 1981). Species showing a significant difference in the comparisons of the oiled samples with the controls are shown in Table 3. The polychaetes Capitella 'capitata', Boccardia sp., Dodecaceria sp. and Sf. Syllinae sp. 1 and Oligochaete sp. 1 had significantly higher representation at the oiled sites, and Platyhelminth sp. 1 , the isopods $L$. stephenseni and $V$. nelladanae and the siphonariid mollusc Kerguelenella lateralis, significantly higher representation at the controls.

\section{Correlations with abiotic variables}

The results of the analysis of sediments for PAH residues are summarised graphically in Fig. 7. While the results indicate that the oiled sites contained levels 

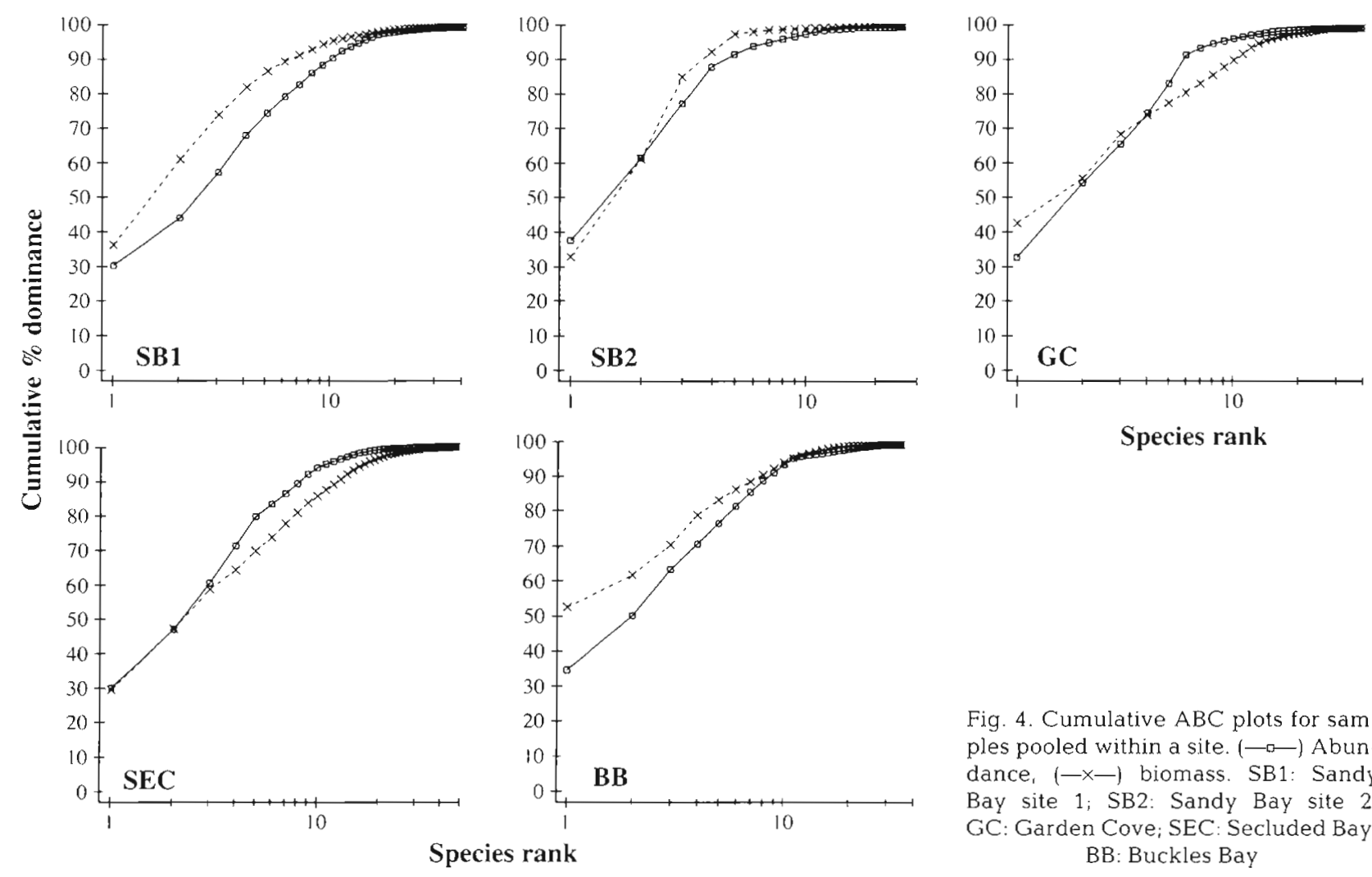

Fig. 4. Cumulative $A B C$ plots for samples pooled within a site. (- - - ) Abundance, $(-x-)$ biomass. SB1: Sandy Bay site 1; SB2: Sandy Bay site 2; GC: Garden Cove; SEC: Secluded Bay; BB: Buckles Bay

of PAH of up to $12 \mathrm{mg}$ per $5 \mathrm{~g}$ of sediment, there was considerable variability within a site. The highest individual values were found at both Buckles Bay and Garden Cove while lower values were consistently

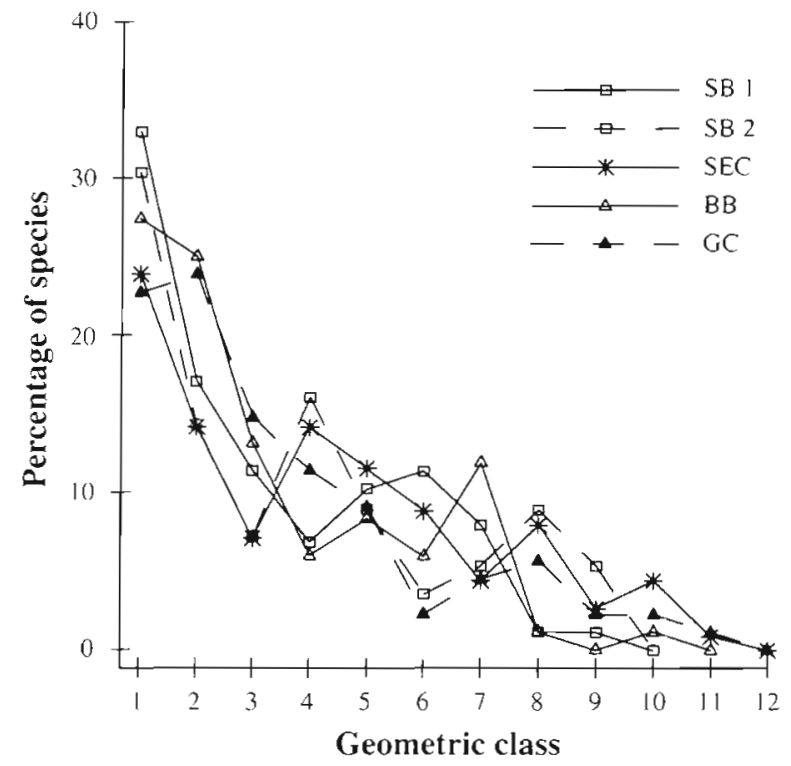

Fig. 5. Log-normal plots for species abundance data pooled across samples from each site (4 samples used from each site). SB1. Sandy Bay site 1; SB2: Sandy Bay site 2; SEC: Secluded Bay; BB: Buckles Bay; GC: Garden Cove detected at Secluded Bay. Although the control sites were located some $6 \mathrm{~km}$ from the site of the oil spill (Fig. 1), the sediment from these samples also contained traces of PAH.

Despite the very obvious differences between the biological composition of the holdfast samples and the gradient of sediment oil residues, the results of correlation analysis between the biotic and environmental similarity matrices (BIO-ENV) indicated that the volume of the holdfast, sediment content and sediment

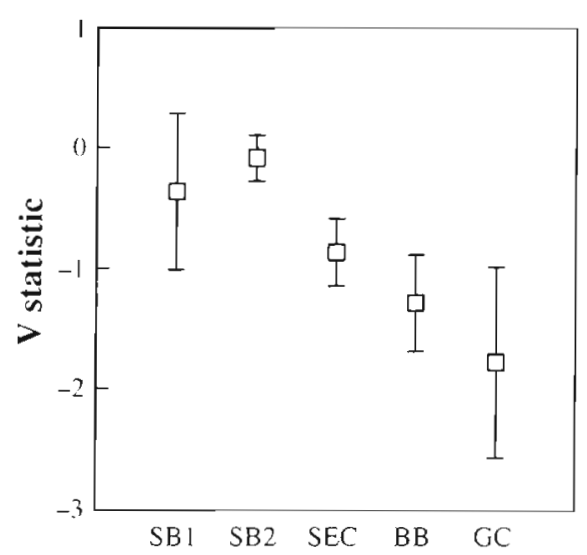

Fig. 6. Means and standard errors for values of the $V$ statistic for each site. SB1: Sandy Bay site 1; SB2: Sandy Bay site 2; SEC: Secluded Bay; BB: Buckles Bay; GC: Garden Cove 
PAH residues had poor explanatory power. Low and non-significant regression coefficients were recorded for each factor separately as well as for all possible combinations of the 3 factors. The largest correlation coefficients were recorded for sediment PAH content $(r=0.079)$ and holdfast volume $(r=-0.151)$, all of the combinations of variables accounting for less variance than these single factors.

Correlation analyses between the standardised, transformed species abundance data and measures of the abiotic variables provided some significant results
(Table 4). Three species (Limnoria stephenseni, Vermectias nelladanae and Platyhelminth sp. 1) had significant negative correlations and 1 species (Sf. Syllinae sp. 1) a significant positive correlation with sediment PAH content. There was a larger number of species which showed significant associations with holdfast sediment content, 5 species with positive correlations (Oligochaete sp. 1, Chone sp., Boccardia sp., Dodecaceria sp. and Mite sp.) and 2 species with significant negative correlations (Hyale novaezealandiae and $L$. stephensenI). Three of the common species showed significant associ-

Table 2. Results of pairwise SIMPER comparisons listing species contributing the most to the differences between the 3 locations (heavily oiled, moderately oiled and controls)

\begin{tabular}{|c|c|c|c|c|c|c|}
\hline & \multicolumn{2}{|c|}{ Moderately oiled } & \multicolumn{2}{|c|}{ Control } & \multirow[t]{2}{*}{$\%$ Contribution } & \multirow{2}{*}{$\begin{array}{c}\text { Cumulative } \\
\%\end{array}$} \\
\hline & Mean & $\mathrm{SD}$ & Mean & SD & & \\
\hline Boccardia sp. & 0.11 & 0.12 & 0.00 & 0.00 & 5.77 & 5.77 \\
\hline Limnoria stephenseni & 0.01 & 0.01 & 0.26 & 0.16 & 5.40 & 11.16 \\
\hline Dodecaceriasp. & 0.07 & 0.05 & 0.00 & 0.00 & 5.21 & 16.37 \\
\hline Vermectias nelladanae & 0.00 & 0.00 & 0.05 & 0.05 & 4.93 & 21.30 \\
\hline Oligochaete sp. 1 & 0.20 & 0.10 & 0.04 & 0.06 & 4.80 & 26.10 \\
\hline Capitella 'capitata' & 0.02 & 0.02 & 0.00 & 0.00 & 4.22 & 30.32 \\
\hline Chone sp. & 0.27 & 0.15 & 0.08 & 0.07 & 4.05 & 34.36 \\
\hline Platyhelminth sp. 1 & 0.00 & 0.00 & 0.02 & 0.01 & 3.73 & 38.10 \\
\hline Nematodes & 0.01 & 0.02 & 0.01 & 0.03 & 3.10 & 41.19 \\
\hline Sf. Syllinae sp. 1 & 0.01 & 0.00 & 0.00 & 0.01 & 3.08 & 44.28 \\
\hline Mite sp. & 0.01 & 0.01 & 0.01 & 0.01 & 3.04 & 47.32 \\
\hline \multirow[t]{3}{*}{ Sf. Eusyllinae sp. 1} & 0.03 & 0.03 & 0.01 & 0.01 & 2.93 & 50.25 \\
\hline & \multicolumn{2}{|c|}{ Heavily oiled } & \multicolumn{2}{|c|}{ Control } & $\%$ Contribution & Cumulative \\
\hline & Mean & $\mathrm{SD}$ & Mean & $\mathrm{SD}$ & & $\%$ \\
\hline Limnoria stephenseni & 0.00 & 0.00 & 0.26 & 0.16 & 7.75 & 7.75 \\
\hline Sf. Syllinae sp. 1 & 0.06 & 0.05 & 0.00 & 0.01 & 5.24 & 12.99 \\
\hline Vermectias nelladanae & 0.00 & 0.00 & 0.05 & 0.05 & 4.67 & 17.66 \\
\hline Laevilittorina caliginosa & 0.09 & 0.10 & 0.23 & 0.15 & 4.37 & 22.03 \\
\hline Capitella 'capitata' & 0.03 & 0.04 & 0.00 & 0.00 & 4.32 & 26.35 \\
\hline Platyhelminth sp. 1 & 0.00 & 0.00 & 0.02 & 0.01 & 4.03 & 30.38 \\
\hline Boccardia sp. & 0.02 & 0.03 & 0.00 & 0.00 & 3.72 & 34.10 \\
\hline Chone sp. & 0.24 & 0.17 & 0.08 & 0.07 & 3.65 & 37.75 \\
\hline Hyale novaezealandiae & 0.10 & 0.13 & 0.13 & 0.06 & 3.65 & 41.40 \\
\hline Spirorbis aggregata & 0.05 & 0.05 & 0.02 & 0.03 & 3.23 & 44.63 \\
\hline Oligochaete sp. 1 & 0.08 & 0.15 & 0.04 & 0.06 & 3.07 & 47.70 \\
\hline \multirow[t]{3}{*}{ Kerguelenella lateralis } & 0.01 & 0.01 & 0.02 & 0.03 & 2.92 & 50.62 \\
\hline & \multicolumn{2}{|c|}{ Heavily oiled } & \multicolumn{2}{|c|}{ Moderately oiled } & $\%$ Contribution & Cumulative \\
\hline & Mean & $\mathrm{SD}$ & Mean & $\mathrm{SD}$ & & $\%$ \\
\hline Mite sp. & 0.00 & 0.00 & 0.01 & 0.01 & 4.93 & 4.93 \\
\hline Sf. Eusyllinae sp. 1 & 0.00 & 0.01 & 0.03 & 0.03 & 4.74 & 9.67 \\
\hline Parawaldeckia kidderi & 0.27 & 0.29 & 0.05 & 0.04 & 4.41 & 14.08 \\
\hline Oligochaete sp. 1 & 0.08 & 0.15 & 0.20 & 0.10 & 4.16 & 18.24 \\
\hline Laevilittorina caliginosa & 0.09 & 0.10 & 0.10 & 0.08 & 3.93 & 22.17 \\
\hline Dodecaceria sp. & 0.01 & 0.02 & 0.07 & 0.05 & 3.70 & 25.86 \\
\hline Hyale novaezealandiae & 0.10 & 0.13 & 0.03 & 0.02 & 3.49 & 29.35 \\
\hline Sf. Syllinae sp. 1 & 0.06 & 0.05 & 0.01 & 0.00 & 3.30 & 32.65 \\
\hline Boccardia sp. & 0.02 & 0.03 & 0.11 & 0.12 & 3.11 & 35.76 \\
\hline Capitella 'capitata' & 0.03 & 0.04 & 0.02 & 0.02 & 3.02 & 38.78 \\
\hline Cirratulus sp. & 0.00 & 0.00 & 0.00 & 0.00 & 2.90 & 41.68 \\
\hline Munna sp. & 0.00 & 0.00 & 0.00 & 0.00 & 2.81 & 44.49 \\
\hline Spirorbis aggregata & 0.05 & 0.05 & 0.05 & 0.11 & 2.80 & 47.29 \\
\hline Limnoria stephenseni & 0.00 & 0.00 & 0.01 & 0.01 & 2.69 & 49.98 \\
\hline Chone sp. & 0.24 & 0.17 & 0.27 & 0.15 & 2.54 & 52.51 \\
\hline
\end{tabular}


Table 3. Species showing a significant location effect in the planned ANOVA comparison of oiled locations vs control location

\begin{tabular}{|c|c|c|}
\hline & $F$ & Sig. \\
\hline Platyhelminth $\mathrm{sp} .1^{\mathrm{a}}$ & 39.66 & $\cdot$ \\
\hline Capitella 'capitata' & 41.02 & $\cdot$ \\
\hline Boccardia sp. & 132.03 & $\cdots$ \\
\hline Dodecaceria sp. ${ }^{a}$ & 29.53 & $\cdot$ \\
\hline Kerguelenella lateralis ${ }^{d}$ & 34.19 & $\cdot$ \\
\hline Vermectias nelladanae & 49.73 & $\cdot$ \\
\hline Limnoria stephenseni ${ }^{\circ}$ & 99.65 & $\cdots$ \\
\hline Oligochaete sp. $1^{b}$ & 7.56 & $\cdot$ \\
\hline Sf. Syllinae sp. $1^{\text {b }}$ & 9.21 & $\cdots$ \\
\hline \multicolumn{3}{|c|}{$\begin{array}{l}{ }^{\circ} \mathrm{df}=1,2 ;{ }^{b} \mathrm{df}=1,21 \text { (tests using the pooled mean square } \\
\cdot \mathrm{p} \leq 0.05 ; \cdot \mathrm{p} \leq 0.001\end{array}$} \\
\hline
\end{tabular}

ations with holdfast volume, L. stephenseni with a negative correlation and Sf. Syllinae sp. 1 and Capitella 'capitata' with positive correlations. The interpretation of the results of these analyses however is confounded by the fact that samples with high sediment content were generally found at the oiled sites and consequently had high levels of residual PAH. This is reflected in the correlation coefficient between holdfast sediment content and $\mathrm{PAH}$ residue, which just fails to reach significance at the $5 \%$ level $(r=0.429$, $\mathrm{df}=15)$.

\section{Interpretation with respect to pre-impact data}

At the time holdfasts were collected for this study, the authors were unaware of any data on holdfast com-

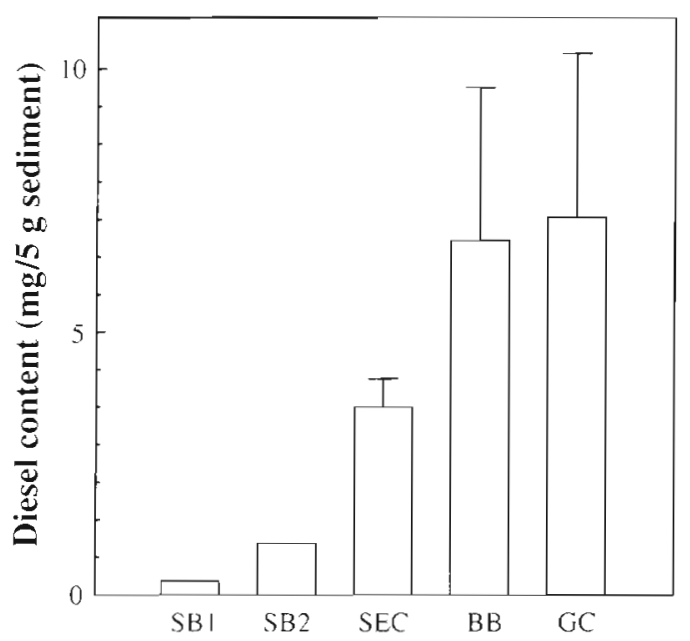

Fig. 7. Means and standard errors of measurements of aromatic hydrocarbon content for holdfast sediment samples from each site. Sediment samples were pooled across samples within Sandy Bay sites 1 and 2 to give 1 reading only for these sites. SB1. Sandy Bay site 1; SB2: Sandy Bay site 2; SEC: Secluded Bay; BB: Buckles Bay; GC: Garden Cove
Table 4. List of species showing significant correlations with the 3 abiotic variables evaluated. There are $22 \mathrm{df}$ for the correlations with holdfast volume and sediment content but only $15 \mathrm{df}$ for PAH residue due to the pooling of some samples for PAH evaluations

\begin{tabular}{|c|c|}
\hline \multicolumn{2}{|l|}{ Sediment PAH content } \\
\hline Platyhelminth sp. 1 & $-0.641 \cdots$ \\
\hline Sf. Syllinae sp. 1 & $0.571^{\circ}$ \\
\hline Vermectias nelladanae & $-0.554^{\circ}$ \\
\hline Limnoria stephenseni & $-0.703 \cdots$ \\
\hline \multicolumn{2}{|l|}{ Sediment per $100 \mathrm{ml}$ holdiast } \\
\hline Oligochaete sp. 1 & $0.636^{\cdots}$ \\
\hline Chone sp. & $0.435^{\circ}$ \\
\hline Boccardia sp. & $0.698 \cdots$ \\
\hline Dodecaceria sp. & $0.748 \cdots$ \\
\hline Limnoria stephenseni & $-0.474^{\circ}$ \\
\hline Hyale novaezealandiae & $-0.467^{\circ}$ \\
\hline Mite sp. & $0.604^{\cdots}$ \\
\hline \multicolumn{2}{|l|}{ Holdfast volume } \\
\hline Limnoria stephenseni & $-0.470^{\circ}$ \\
\hline Sf. Syllınae sp. 1 & $0.487^{\circ}$ \\
\hline Capitella 'capitata' & $0.649^{\cdots}$ \\
\hline$\cdot p<0.05, \cdots p<0.01, \cdots p<0.001$ & \\
\hline
\end{tabular}

munity structure from any site prior to the oiling in 1987. Recently, however, data have been provided for 5 holdfasts collected from Buckles Bay in October 1983 (G. Edgar unpubl. data). These data were therefore incorporated into the analysis of biotic differences between sites in order to reduce the confounding resulting from the lack of pre- and post-impact data

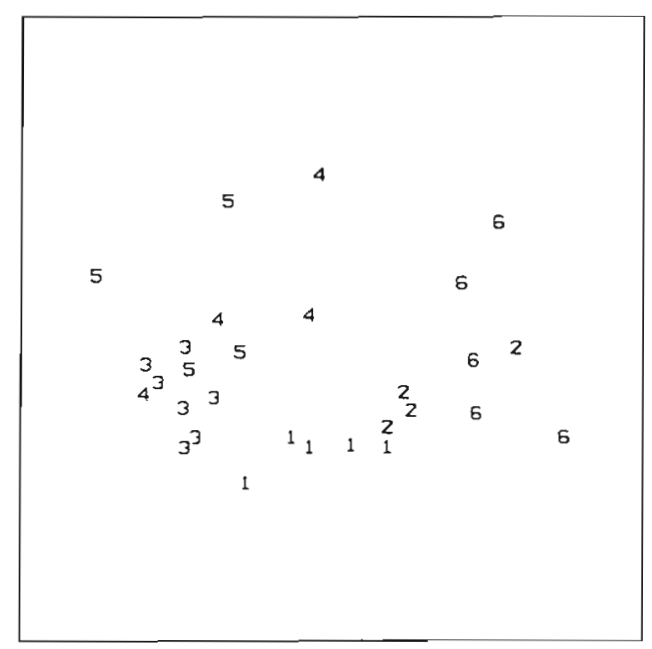

Fig. 8. MDS plot for data aggregated to a mixed taxonomic level, including data from samples collected at Buckles Bay in 1983. Kruskal's stress $=0.159$. Symbols: $1=$ Sandy Bay site $1 ; 2=$ Sandy Bay site 2; 3 = Secluded Bay; $4=$ Buckles Bay; $5=$ Garden Cove; $6=$ Buckles Bay 1983. As the analysis was non-metric, axis scales are arbitrary and are therefore omitted 

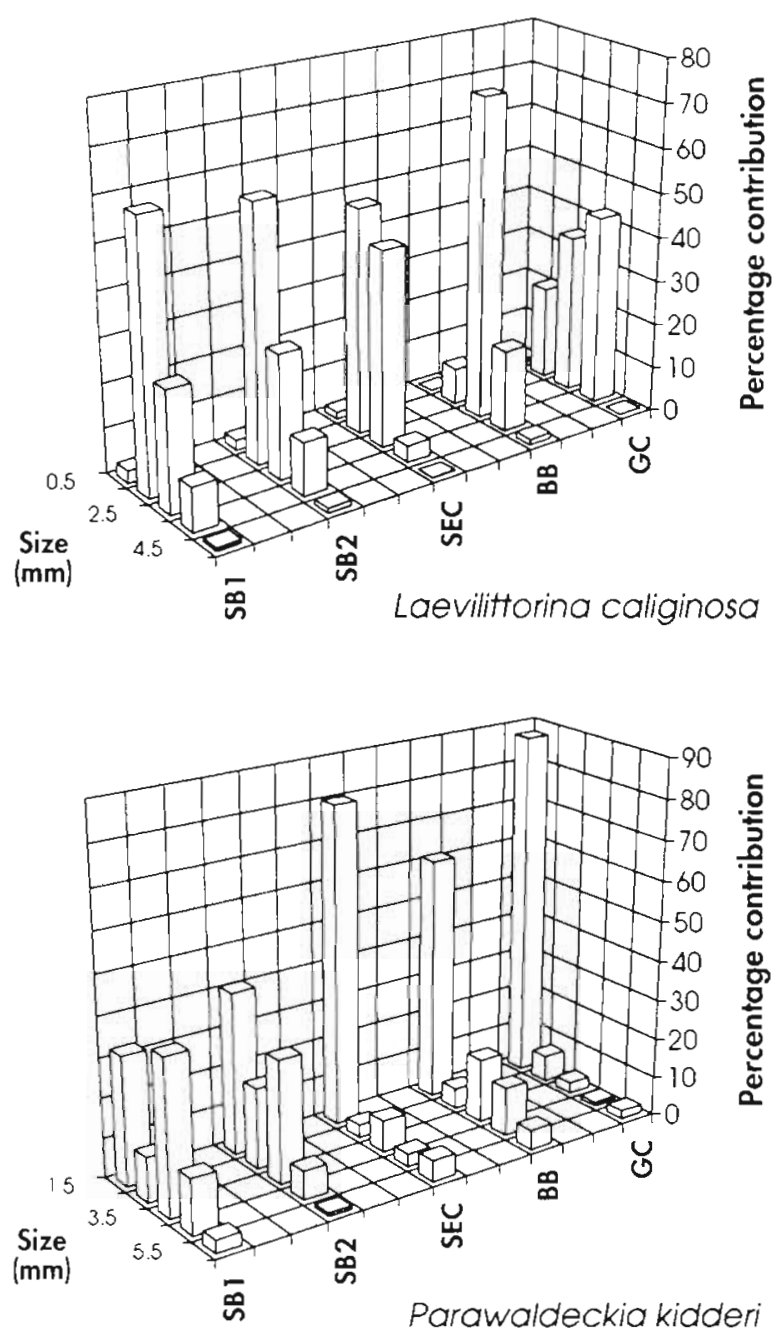
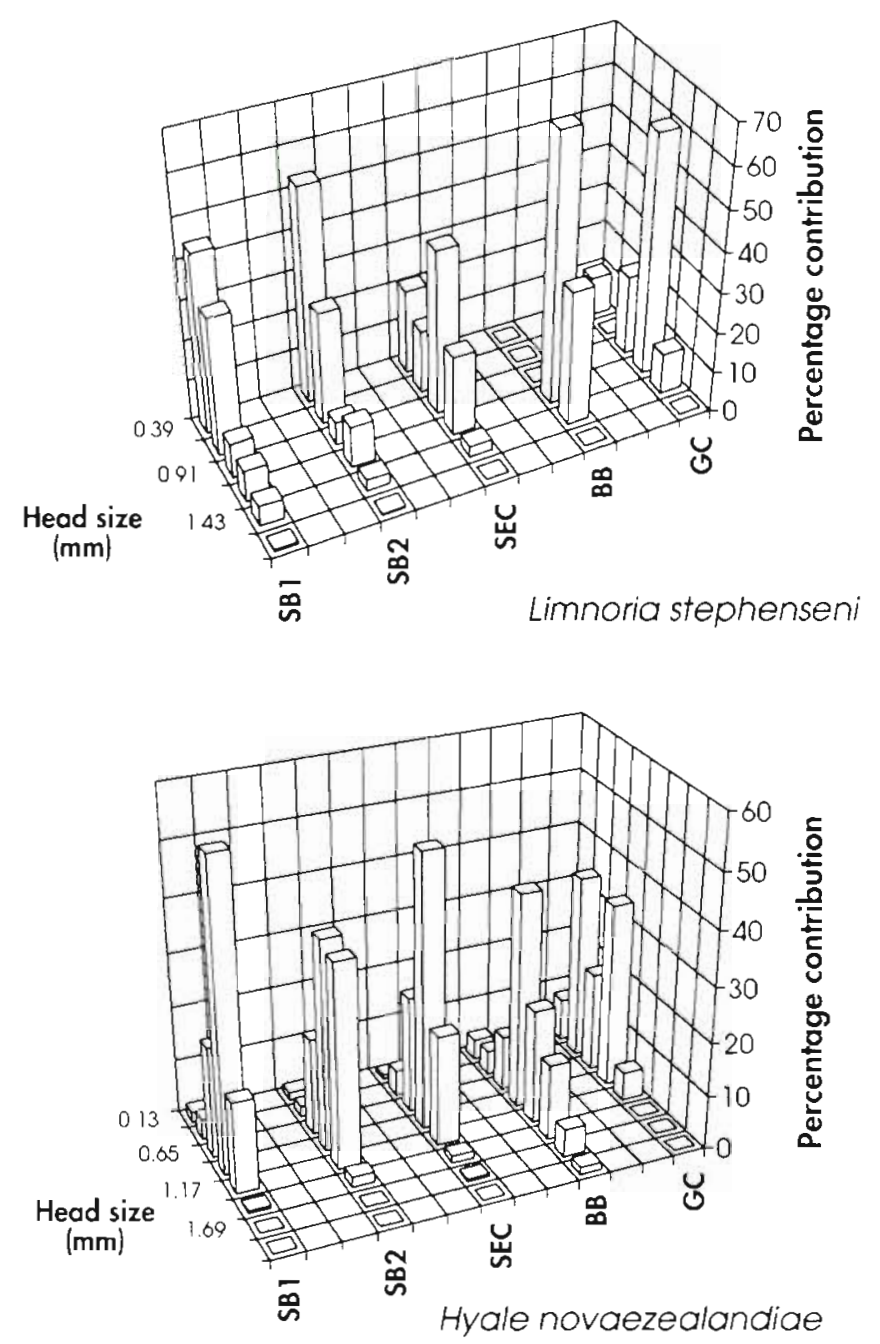

Fig. 9. Size distributions for populations of the 4 most common species occurring in the Durvillaea antarctica holdfast. SB1: Sandy Bay site 1; SB2: Sandy Bay site 2; SEC: Secluded Bay; BB: Buckles Bay; GC: Garden Cove

from all sites in interpreting possible oil effects. Because a number of species in the pre-impact data for Buckles Bay were not identified to species level and identification codes do not correspond to those used in the present study, MDS analysis was conducted at the mixed taxonomic level only. The results (Fig. 8) show that the pre-impact samples from Buckles Bay group to the right of the MDS plot, overlapping with those from the control site, Sandy Bay 2. The important ANOSIM results are that there is a highly significant difference between pre-and post-impact samples from Buckles Bay $(p=0.008)$ and no significant difference between samples from Sandy Bay 2 and pre-impact data from Buckles Bay ( $p=0.333)$. The results of SIMPER breakdowns further indicate that the significant differences between the 2 sets of samples from Buckles Bay are primarily attributable to substantial increases in the proportions of polychaetes ffrom a 1983 mean of $4 \%$ of the total abundance to a mean of $43 \%$ in 1989), oligochaetes ( $0 \%$ to $2 \%$ ) and amphipods ( $21 \%$ to $42 \%$ ) and a decrease in the proportion of gastropods $162 \%$ to $9 \%$ ). Differences in the proportions of these taxa account for $50 \%$ of the differences between the 2 sets of samples.

\section{Differences at the population level}

Histograms of the size distribution for each of the 4 common species are shown in Fig. 9. In the ANOVA testing differences in mean size, the location effect was tested over the pooled site within location and residual error terms for Laevilittorina caliginosa and Parawaldeckia kidderi but this was not appropriate for either Hyale novaezealandiae or Limnoria stephenseni (Sokal \& Rohlf 1981). 


\section{Laevilittorina caliginosa}

Size distribution data (Fig. 9) for the control sites were very similar, with the population distribution skewed to smaller individuals. Although the smaller size classes were present at all sites, both the moderately oiled and heavily oiled sites showed a higher dominance of medium to larger sized animals. This was particularly evident for samples from the 2 heavily oiled sites (Buckles Bay and Garden Cove).

There were no significant differences between the mean sizes of Laevilittorina caliginosa between sites within locations $(F=1.55, \mathrm{df}=2,16)$. The location effect was significant $(F=11.66, \mathrm{df}=2,18, \mathrm{p}<0.01)$ and planned comparisons of oiled locations versus controls and moderately oiled versus heavily oiled locations both revealed significant differences $(F=8.04$, $\mathrm{df}=1,18, \mathrm{p}<0.05$ and $F=9.42, \mathrm{df}=1,18, \mathrm{p}<0.01$ respectively).

\section{Limnoria stephenseni}

Head size was found to be a good predictor of total body length for Limnoria stephenseni, the relationship being described by the following formula: Total body length $(\mathrm{mm})=13 \times$ Head size $(\mathrm{mm})-2.5(\mathrm{r}=0.97$, $\mathrm{df}=18, \mathrm{p}<0.001)$

Comparisons of the size class frequency between sites indicated considerable differences between the different levels of oiling (Fig. 9). Samples from the heavily oiled sites mainly comprised larger animals with no individuals in the smaller size classes. In contrast, the 2 control sites, which had similar size distribution curves, were dominated by smaller individuals. The samples from Secluded Bay contained the full range of sizes and were dominated by medium sized individuals. There were no significant differences in the mean size of individuals between sites within locations $(F=1.97 \mathrm{df}=2,16)$ or for the location term $(F=9.50, \mathrm{df}=2,2)$. However, planned comparisons revealed a significant difference for the comparison of all oiled sites with the controls $(F=17.94$, $\mathrm{df}=1,2, \mathrm{p}<0.05$ ). Comparisons between the moderately oiled and heavily oiled sites were not significant $(F=2.38$, df $=1,2)$.

\section{Parawaldeckia kidderi}

Size distribution patterns were markedly different for the control and oiled sites for Parawaldeckia kidderi (Fig. 9). While control sites were dominated by small and medium sized individuals, all oiled sites showed an overwhelming dominance of individuals in the smallest size class $196 \%$ for samples from Garden
Cove). In addition, the largest individuals were consistently recorded in samples from all oiled sites.

There were no significant differences in mean sizes between sites within locations $(F=0.77, \mathrm{df}=2,16)$ or in the planned comparison between the moderately oiled and heavily oiled locations $(F=0.09$, df $=1,18)$. The location term was significant $(F=4.94$, df $=2,18, \mathrm{p}<$ $0.05)$ as was the planned comparison between oiled locations and the controls $(F=9.42$, df $=1,18, p<0.01)$.

\section{Hyale novaezealandiae}

Head size was found to be a good predictor of total body length for Hyale novaezealandiae, the relationship being described by the following formula: Total body length $(\mathrm{mm})=14.2 \times$ Head size $(\mathrm{mm})-1.27$ ( $r=0.99$, df $=18, p<0.001)$.

Most sites showed a dominance of medium sized individuals in the size distribution histograms (Fig. 9) with similar distributions for the control sites and Secluded Bay. The difference between the distributions for the sites within the heavily oiled location (Buckles Bay with a distribution skewed towards larger and Garden Cove towards smaller individuals) would appear to be the primary reason for the significant site within location effect in the statistical analysis $(F=7.16, \mathrm{df}=2,16, \mathrm{p}<0.01)$. All the other terms in the ANOVA were not significant.

\section{DISCUSSION}

Previous descriptions of the Durvillaea antarctica holdfast environment have noted that the majority of macrofaunal species are resident within the holdfast either in the area between the base of the holdfast and the rocky substratum or in chambers excavated by activities of herbivorous invertebrate species (Herriott 1923, Oliver 1923, Kenny \& Haysom 1962, Cancino \& Santelices 1981). These descriptions have generally made the assumption that the herbivores on which the other fauna are dependent for space provision are primarily molluscan. The present study suggests that the activities of the herbivorous isopod Limnoria stephenseni are of much greater importance in the Macquarie Island holdfast habitat. In addition, the structure of the habitat, ranging from a series of small, often interlinked chambers to 1 larger chamber, would appear to be more heterogeneous than for the same species of kelp in central Chile where Cancino \& Santelices (1981) recorded only single, large chambers in D. antarctica holdfast samples. All major tunnels and chambers examined within the samples from the control sites in Sandy Bay were associated with the activi- 
ties of $L$. stephenseni, with the longer and wider tunnels attributable to larger adult specimens and smaller chambers often associated with aggregations of small, recently recruited juveniles.

The results of the evaluation of differences in spatial pattern for the Durvillaea antarctica holdfast community suggest that the 'Nella Dan' oil spill has had a considerable effect on the faunal complement. However, prior to discussing these more fully it should be noted that the present study did not include pre-impact measurements from all sites and therefore the results need to be cautiously interpreted. The inferences drawn from the results are aided by the availability of data collected from Buckles Bay in 1983 and also by the 1988-89 study design which incorporated 2 control sites. Despite these concerns, the differences in community structure demonstrated between the different treatments are highly suggestive of an oil effect and the types and magnitudes of differences are consistent with other published accounts of oil spills on benthic faunal communities.

The major impact appears to have been on the population of Limnoria stephenseni with very few individuals recorded from the samples taken within the oiled locations (representing $0.3 \%$ of the total number of individuals). In contrast, this species was numerically dominant in samples from the control sites (accounting for $27 \%$ of the total number of individuals) and third most dominant in pre-impact samples from Buckles Bay (although representing only $2.3 \%$ of the total number of individuals; G. Edgar unpubl. data). The size distribution data for $L$. stephenseni further suggest that mortality occurred across the full range of animal sizes. Individuals that were found in samples from the oiled sites during this study were generally large and were found burrowing into the holdfast from the dorsal surface. In contrast, most tunnels in samples from the control sites did not penetrate the dorsal surface of the holdfast, primarily radiating from internal chambers. This may indicate that the few L. stephenseni collected from the oiled sites have migrated from areas that were unaffected by the oil spill.

There is evidence that Limnoria stephenseni has had an historical presence in the holdfasts sampled from the oiled sites, as most have internal chambers and tunnels consistent with the activities of these herbivorous isopods (Fig. 2). However, with the exception of a few fresh tunnels leading from the external dorsal surface of some holdfast samples, the internal chambers and tunnels were lined with a hard, dark layer (possibly representing a protective growth; Herriott 1923). Tunnels of this kind seldom contained individuals of $L$. stephenseni in control samples, with specimens primarily present in freshly excavated areas in which there was no darker lining. No fresh tunnels were observed in the internal areas of any of the samples from the oiled sites. Another species which was also much less common at the oiled sites was the small isopod Vermectias nelladanae, which was present in moderate abundance at the control sites. Only 2 individuals of this species were found at the oiled sites, both occurring in 1 sample from Garden Cove. However, this species was also absent from Buckles Bay samples in 1983.

There was no significant difference in the proportions of the other species of peracarid crustaceans among treatments despite the documented susceptibility of this faunal group to oil pollution. Indeed the results within the peracarids contrast markedly with studies on the toxicity of oil in the Arctic region which suggested that isopods were more tolerant than amphipods (Wells \& Percy 1985). However, while there were no differences in the proportions of Parawaldeckia kidderi between locations, the evaluation of size distribution patterns indicated a major difference between all oiled sites and the controls. These differences suggest that medium sized individuals are under-represented at the oiled sites, with small individuals dominating. A tentative explanation is that there was a high mortality of $P$. kidderi following the oiling. Subsequent migration of larger adults (the largest specimens were consistently recorded from the oiled sites) and a recent, very large recruitment of juveniles has resulted in similar densities to the control sites but with markedly different patterns of size distribution. As both pre-impact data on size distributions and details of the life history of this species are not available, this explanation remains speculative.

Samples from the oiled sites contained a number of species which were not recorded from the controls or from pre-impact samples from Buckles Bay. These were the opportunistic polychaete Capitella 'capitata' and species of cirratulids and terebellids. In addition, there were a number of polychaete species that, although present occasionally and in low abundance at the control sites, were abundant in samples from the oiled sites. This applied in particular to the spionid Boccardia sp. The presence of high abundances of representatives of these families in samples from the oiled sites is consistent with observations made during investigations into the effects of oiling elsewhere (Conan 1982, Berge 1990, Bonsdorff et al. 1990). The presence of $C$. 'capitata' is of particular note as this species has been identified as being resistant to hydrocarbons and one of the main indicators of oil pollution (Michael 1977, Scott-Carr \& Reish 1977, Gray 1981, Gray et al. 1990, Pocklington \& Wells 1992). Similar findings have recently been reported from Antarctic waters where $C$. capitata antarctica dominated soft 
sediments in areas of highest hydrocarbon pollution adjacent to McMurdo Station, but was absent from unpolluted reference sites (Lenihan et al. 1990).

The dominant molluscan species Laevilittorina caliginosa displayed no apparent differences in patterns of dominance among treatments. This is consistent with studies of this family in lower latitudes which have demonstrated considerable tolerance to oiling in the majority of cases (Stirling 1977, Nelson 1982) although heavy oiling during the 'Amoco Cadiz' oil spill did result in substantial losses ( 50 to $99 \%$ ) of Littorina on the French coast (Chassé 1978). An examination of the size distribution data, however, suggests that there are some consistent differences between locations. While the size distribution patterns are similar for the controls and Secluded Bay, the heavily oiled sites supported fewer smaller individuals and a greater proportion of larger individuals. This is particularly apparent for samples collected at Garden Cove (Fig. 9). This observation possibly suggests a differential mortality of small animals during the oiling.

The results also suggest that the oiling had an impact on populations of another mollusc, the siphonariid Kerguelenella lateralis. This species was present in low abundance and the comparisons between oiled and control sites indicated significantly lower abundances at the oiled sites. Pople et al. (1990) indicated that this species was absent from the collection of beached fauna made immediately following the oil spill despite high densities in the Bare and Upper Red zones. This may be due to the predominance of this species on the upper shore, outside the range of the main impact of the oiling (Pople et al. 1990). The present results suggest that $K$. lateralis may be sensitive to the effects of oil where exposure is more direct.

Each of the 3 methods used to assess the community for evidence of stress revealed a difference between the different sites. The Ewens/Caswell neutral model analysis indicated that the control sites, although returning negative values of $V$, had diversity values closer to the expectation under the null hypothesis of no species interactions than all sites from the oiled locations. There was an apparent gradient of mean $V$ values at the other sites, with the most negative values from Buckles Bay and Garden Cove within the heavily oiled location. Negative values of $V$ imply excessive dominance within the community (Warwick 1993), which is a feature of perturbed habitats (Pearson \& Rosenberg 1978). However, the few studies that have used this method have indicated considerable variation in the results, making the interpretation of the trends difficult (Warwick 1993). For example, in a study of the effect of an outfall of domestic effluent on kelp holdfast fauna, Smith \& Simpson (1992) found that while control and impacted sites had negative values of $V$, the perturbed sites had less negative values than the controls. The interpretation offered for this observation was that species interactions were reduced by the provision of organic material which could be used as a food source and that competitive interactions resulted in the greater negative deviations recorded from the controls. Thus, in comparison to the values recorded from respective control sites, the deviations recorded at impacted sites by Smith \& Simpson (1992) and the present study are in opposite directions. A possible explanation for this difference is that the types of pollutants investigated and the duration of the environmental stress are different in each case. The present study investigated a pulse stress which can be expected to have a primarily toxic impact on the biota. In contrast, Smith \& Simpson (1992) investigated a press stress involving organic enrichment at concentrations which would be unlikely to have a large toxic effect. Although the results of the neutral model analysis provide an additional method by which stress can be evaluated in benthic communities, problems with the interpretation of the results are likely to persist until an empirical framework of expected behaviour under differing types of stress can be erected. This can only be done with more extensive application of the method to a range of environmental studies.

The log-normal plots indicate that the 3 oiled sites are more stressed than the controls, as the curves for samples from Secluded Bay, Buckles Bay and Garden Cove span more geometric classes and have lower percentages of rare species (Class 1) than the 2 control sites (Gray \& Pearson 1982). In this analysis, samples from Buckles Bay appear intermediate in their levels of stress, with higher contributions of rare species and a lower span of classes than the samples from Garden Cove and Secluded Bay. This trend is also apparent for the $A B C$ curves, which demonstrate the perturbed configuration for samples from Garden Cove and Secluded Bay but an unperturbed configuration at Buckles Bay.

These results suggest that samples from Buckles Bay were less stressed despite the fact that this was the site of the grounding and the area first impacted by the oil slick. The results of the MDS analyses at both the species and mixed taxonomic level, however, do not echo this apparent intermediacy, with data points for Buckles Bay lying adjacent to those for Garden Cove and Secluded Bay (Fig. 3A, B).

Comparisons between this study of holdfast fauna and the intertidal studies on the effects of the same oil spill are hampered by the fact that although some of the species investigated by Pople et al. (1990) were present within the holdfast, the primary indicator of the oil impact (the limpet Nacella macquariensis) was not found in any holdfast sample. The only other species common 
to both studies were the chitons Hemiarthrum setulosum and Plaxiphora aurata and the asteroid Anasterias directa. Both $P$. aurata and $A$. directa were rare within the holdfast habitat (with a total of 1 and 5 individuals respectively), precluding an evaluation of their patterns of distribution among sites. $H$. setulosum was also uncommon in the holdfast habitat and patchily distributed among samples from all sites.

The studies by Pople et al. (1990) indicated that biota on the lower intertidal areas of the moderately oiled location had densities intermediate between the controls and the heavily oiled sites. This distinction is not as apparent in the present study, with the faunal complement of all oiled sites showing similarities. Perhaps the most important link between the 2 oiled locations in this context is the comparative rarity of Limnoria stephenseni, the species upon which the rest of the faunal complement are primarily dependent for the provision of space within the holdfast habitat. We further hypothesise that in the absence of this species, the lack of activity within the central area of the holdfast may facilitate the accumulation of sediment and other debris which would otherwise have been resuspended, reworked and eliminated from the internal chambers. The accretion of sediment in itself is sufficient to cause a change in the community structure to one dominated by fauna dependent on sediment for either food or as a subhabitat within the holdfast. Indeed, this may be an important secondary cause of differences between sites, as samples collected from Buckles Bay prior to the oil spill showed no signs of sediment accretion (G. Edgar pers. comm.). This suggests both a primary and secondary effect of the oil spill on the holdfast community involving at least 2 of the suite of effects of oil on benthic communities nominated by Moore \& Dwyer (1974): (1) direct toxicity and (2) longer-term modification of the habitat. In addition the presence of hydrocarbon residues within the sediment may limit the fauna to opportunistic species with tolerance to these persistent oil fractions.

While the results of this study have demonstrated considerable differences between oiled and unoiled sites at both the community and population level, there are a number of alternative hypotheses that remain untested. This is primarily due to the lack of preimpact data from all sites. Further sampling of the study sites is planned in order to provide additional data on spatial differences between sites and the longterm recovery of the holdfast macrofaunal community.

Acknowledgements. We thank Tony Pople for collecting the holdfast samples during the summer of 1988-89. Dr Stuart Cairns made helpful comments on the manuscript, Nicole Hacking helped with the dissection and sorting of some of the holdfast material and Dr David Tucker supervised the analysis of PAH residues in the holdtast sediment samples.
Most of the statistical procedures used in this study were conducted using the PRIMER computer programs from Plymouth Marine Laboratory, Plymouth, UK. Consequently, we thank Drs R. M. Warwick and K. R. Clarke for making both the software and documentation available. The following people assisted with the identification of the holdfast fauna: Dr Gary Poore (isopods), Dr Pat Hutchings (worms), Mr Ian Loch (molluscs) and Dr Mary Notestine (mites and insect larvae). Financial support for the study was provided by the Antarctic Science Advisory Committee. Finally we acknowledge Dr G. Edgar for providing pre-impact data from Durvillaea antarctica holdfasts collected at Buckles Bay (October 1983) and also for helpful comments on the manuscript.

\section{LITERATURE CITED}

Bennett I (1971) Shores of Macquarie Island. Rigby Ltd, Sydney

Berge JA (1990) Macrofauna recolonization of subtidal sediments. Experimental studies on defaunated sediment contaminated with crude oil in two Norwegian fjords with unequal eutrophication status. 1. Community responses. Mar Ecol Prog Ser 25:103-115

Bonsdorff E, Bakke T, Pedersen A (1990) Colonization of amphipods and polychaetes to sediments experimentally exposed to oil hydrocarbons. Mar Pollut Bull 21:355-358

Bray JR, Curtis JT (1957) An ordination of the upland forest communities of southern Wisconsin. Ecol Monogr 27 : $325-349$

Cancino J, Santelices B (1981) The ecological importance of kelp-like holdfasts as a habitat of invertebrates in central Chile. In: Levring $T$ (ed) Proc 10th Int Seaweed Symp. Walter de Gruyter, Berlin, p 241-246

Cassie RM (1954) Some uses of probability paper in the analysis of size frequency distribution. Aust $\mathrm{J}$ mar Freshwat Res 42:783-794

Chapman VJ, Chapman DJ (1973) The algae, 2nd edn. Macmillan, London

Chassé $C$ (1978) The ecological impact on and near shores by the Amoco Cadiz oil spill. Mar Pollut Bull 9:298-301

Clarke KR (1993) Non-parametric multivariate analyses of changes in community structure. Aust J Ecol 18:117-143

Clarke KR, Ainsworth M (1993) A method for linking multivariate community structure to environmental variables. Mar Ecol Prog Ser 92:205-219

Conan G (1982). The long-term effects of the Amoco Cadiz oil spill. Phil Trans R Soc Lond B 297:323-333

Dauer DM, Luckenbach MW, Rodi AJ Jr (1993) Abundance biomass comparison ( $\mathrm{ABC}$ method) : effects of an estuarine gradient, anoxic/hypoxic events and contaminated sediments. Mar Biol 116:507-518

Delille D, Vaillant $N$ (1988) Short term biodegradation of crude oil in sub-Antarctic marine area. Proc 5th SCAR Symp Antarctic Biol Hobart 1988. Austrailian Antartic Division, Hobart, p 1-5

Edgar GJ (1987) Dispersal and floral propagules associated with drifting Macrocystis pyrifera plants. Mar Biol 95: $599-610$

Fenwick GD (1985) Life histories of four co-occurring amphipods from a shallow, sand bottom at Kaikoura, New Zealand. NZ J Zool 12:71-105

Field JG, Clarke KR, Warwick RM (1982) A practical strategy for analysing multispecies distribution patterns. Mar Ecol Prog Ser 8:37-52

Gray JS (1981) The ecology of marine sediment. Cambridge University Press 
Gray JS, Aschan M, Carr MR, Clarke KR, Green RH, Pearson $\mathrm{TH}$, Rosenberg R, Warwick RM (1988) Analysis of community attributes of the benthic macrofauna of Frierfjord/ Langesundfjord Norway and in a mecocosm experiment. Mar Ecol Prog Ser 46:151-165

Gray JS, Clarke KR, Warwick RM, Hobbs G (1990) Detection of initial effects of pollution on marine benthos: an example from the Ekofisk and Eldfisk oilfields, North Sea. Mar Ecol Prog Ser 66:285-299

Gray JS, Pearson TH (1982) Objective selection of sensitive species indicative of pollution induced change in benthic communities 1. Comparative methodology. Mar Ecol Prog Ser 9:111-119

Hamilton RW (1988) Macquarie Island foreshore environment survey. Report to Tasmanian Lands, Parks and Wildife, Hobart

Henig H (1979) Quantitative analysis of residual fuel oil in sediments sampled by absorption spectra. Mar. Pollut Bull $10: 234-237$

Herriott EM (1923) Some morphological notes on the New Zealand giant kelp, Durvillaea antarctica [Chamisso]. Trans Proc NZ Inst 54:549-564

Hurlbert SH (1984) Pseudoreplication and the design of ecological field experiments. Ecol Monogr 54:187-211

Jones DJ (1971) Ecological studies on macroinvertebrate communities associated with polluted kelp forests in the North Sea. Helgoländer wiss Meeresunters 23:417-441

Jones DJ (1972) Changes in the ecological balance of invertebrate communities in the kelp holdfast habitat in some North Sea waters. Helgoländer wiss Meeresunters 23 $118-122$

Kenny R, Haysom N (1962) Ecology of rocky shore organisms at Macquarie Island. Pacif Sci 16:245-263

Lambshead PJD, Platt HM (1988) Analysing disturbance with the Ewens/Caswell neutral model theoretical review and practical assessment. Mar Ecol Prog Ser 43:31-41

Lenihan HS, Oliver JS, Oakden JM, Stephenson MD (1990) Intense and localised benthic marine pollution around McMurdo Station, Antarctica. Mar Pollut Bull 21:422-430

Lowry JK, Fenwick GD (1983) The shallow-water gammaridean Amphipoda of the subantarctic islands of New Zealand and Australia: Melitidae, Hadziidae. J R Soc NZ 13:201-260

Lowry JK, Horning DS, Poore GCB, Ricker RW (1978) The Australian Museum Macquarie Island expedition, summer 1977-78. Australian Museum Trust, Sydney

Lowry JK, Stoddart HE (1983) The shallow-water gammaridean Amphipoda of the subantarctic islands of New Zealand and Australia: Lysianassoidea. J R Soc NZ 13:279-294

Michael AD (1977) The effects of petroleum hydrocarbons on marine populations and communities. In: Wolfe DA (ed) Fate and effects of petroleum hydrocarbons in marine ecosystems and organisms. Pergamon Press, Oxford, p $129-137$

Moore PG (1972) Particulate matters in the sublittoral zone of an exposed coast and its ecological significance to the fauna inhabiting kelp holdfasts. J exp mar Biol Ecol 10: $59-80$

Moore PG (1973a) The kelp fauna of Northeast Britain. I Introduction and physical environment. J exp mar Biol Ecol 13:97-125

Moore PG (1973b) The kelp fauna of Northeast Britain. II. Multivariate classification turbidity as an ecological factor. J exp mar Biol Ecol 13:127-163

Moore PG (1974) The kelp fauna of Northeast Britain. III. Quantitative and qualitative ordinations and the utility of a multivariate approach. J exp mar Biol Ecol 16:257-300
Moore SF, Dwyer RL (1974) Effects of oil on marine organisms: a critical assessment of published data. Wat Res 8:819-827

Nelson WG (1982) Experimental studies of oil pollution on the rocky intertidal community of a Norwegian fjord. J exp mar Biol Ecol 65:121-138

Notini M (1978) Long-term effects of an oil spill on Fucus macrofauna in a small Baltic Bay. J Fish Res Bd Can 35: $745-753$

Oliver WRB (1923) Marine and littoral animal communities in New Zealand. Trans Proc NZ Inst 54:496-545

Pearson TH, Rosenberg R (1978) Macrobenthic succession in relation to organic enrichment and pollution of the marine environment. Oceanogr mar Biol A Rev 16:229-311

Platt HM, Lambshead PJD (1985) Neutral model analysis of patterns of marine benthic species diversity. Mar Ecol Prog Ser 24:75-81

Pocklington P, Wells PG (1992) Polychaetes: key taxa for marine environmental quality monitoring. Mar Pollut Bull 24:593-598

Pople A, Simpson RD. Cairns SC (1990) An incident of southern oil pollution: effects of a spillage of diesel fuel on the rocky shore of Macquarie Island (sub-Antarctic). Aust J mar Freshwat Res 41:603-620

Rice SD, Short JW, Karinen JF (1977) Comparative oil toxicity and comparative animal sensitivity. In: Wolfe DA (ed) Fate and effects of petroleum hydrocarbons in marine organisms and ecosystems. Pergamon Press, Oxford, p 78-94

Ricker RW (1987) Taxonomy and biogeography of Macquarie Island seaweeds. British Museum (Natural History), London

Scott Carr R, Reish DJ (1977) The effect of petroleum hydrocarbons on the survival and life history of polychaetous annelids. In: Wolfe DA (ed) Fate and effects of petroleum hydrocarbons in marine organisms and ecosystems. Pergamon Press, Oxford, p 168-173

Sheppard CRC, Bellamy DJ, Sheppard ALS (1980) Study of the fauna inhabiting the holdfasts of Laminaria hyperborea (Gunn.) Fosl. along some environmental and geographical gradients. Mar environ Res 4:25-51

Simpson RD (1976a) The shore environment of Macquarie Island. ANARE sci Rep Ser B (1) Zoology 125

Simpson RD (1976b) Physical and biotic factors limiting the distribution and abundance of littoral molluscs on Macquarie Island (sub-Antarctic). J exp mar Biol Ecol 21:11-49

Simpson RD (1977) The reproduction of some littoral molluscs from Macquarie Island (sub-Antarctic). Mar Biol 44: $125-142$

Simpson RD (1982a) Reproduction and lipids in the subAntarctic limpet Nacella (Patinigera) macquariensis, Finlay, 1927. J exp mar Biol Ecol 56:33-48

Simpson RD (1982b) The reproduction of some echinoderms from Macquarie Island. Aust Mus Mem 16:39-52

Simpson RD (1988) Developments in the studies of subantarctic shores, with particular reference to Macquarie Island. Pap Proc R Soc Tas 122:211-217

Simpson RD, Harrington SA (1985) Egg masses of three gastropods, Kerguelenella lateralis (Siphonariidae), Laevilittorina caliginosa and Macquariella hamiltoni (Littorinidae), from Macquarie Island (sub-Antarctic). J Malacol Soc Aust 7:17-28

Smith SDA (1993) The macrofaunal community of Ecklonia radiata holdfasts: application to monitoring the effects of domestic effluent in the shallow sublittoral environment PhD thesis, University of New England, Australia

Smith SDA (1994) Impact of domestic effluent versus natura background variability: an example from Jervis Bay, south coast New South Wales. Aust J mar Freshwat Res 45(6) $1045-1064$ 
Smith SDA, Simpson RD (1992) Monitoring the shallow sublittoral using the fauna of kelp (Ecklonia radiata) holdfasts. Mar Pollut Bull 24:46-52

Smith SDA, Simpson RD (1993) The effects of pollution on the holdfast macrofauna of the kelp Ecklonia radiata: discrimination at different taxonomic levels. Mar Ecol Prog Ser 96:199-208

Sokal RR, Rohlf FJ (1981) Biometry. The principles and practice of statistics in biological research, 2 nd edn. WH Freeman and $\mathrm{Co}$, New York

Stirling HP (1977) Effects of a spill of marine diesel oil on the rocky shore fauna of Lamma Island, Hong Kong. Environ Pollut 12:93-117

Warwick RM (1986) A new method for detecting pollution effects on marine macrobenthic communities. Mar Biol 92 $557-562$

This article was submitted to the editor
Warwick RM (1988a) Analysis of community attributes of the macrobenthos of Frierfjord/Langesundfjord at taxonomic levels higher than species. Mar Ecol Prog Ser 46: $167-170$

Warwick RM (1988b) The level of taxonomic discrimination required to detect pollution effects on marine benthic communities. Mar Pollut Bull 19:259-268

Warwick RM (1993) Environmental impact studies om marine communities: pragmatıcal considerations. Aust J Ecol 18: $63-80$

Warwick RM, Clarke KR (1994) Relearning the ABC: taxonomic changes and abundance/biomass relationships in disturbed benthic communities. Mar Biol 118:739-744

Wells PG, Percy JA (1985) Effects of oil on Arctic invertebrates. In: Engelhardt FR (ed) Petroleum effects in the Arctic environment. Elsevier, London, p 101-156

Manuscript first received: March 15, 1994

Revised version accepted: January 24, 1995 